Europe's Journal of Psychology 4/2009, pp. 128-145

www.ejop.org

\title{
A Critique of the IQ / Achievement Discrepancy Model for Identifying Specific Learning Disabilities
}

\author{
Albert F. Restori \\ California State University, Northridge \\ Gary S. Katz \\ California State University, Northridge \\ Howard B. Lee \\ California State University, Northridge
}

\begin{abstract}
When the United States Congress passed the Individuals with Disabilities Education Improvement Act in 2004 (IDEIA 2004), local educational agencies (LEA) were permitted to use a Response-to-Intervention (RTI) approach for identifying children with possible learning disabilities for special education. Furthermore, IDEIA 2004 no longer required LEAs to establish an IQ-achievement discrepancy for determining a Specific Learning Disability (SLD). Although federal law no longer mandates the need for an IQachievement discrepancy for determining an SLD, most school psychologists continue to employ this approach for the assessment of children at-risk for SLD. Furthermore, some researchers suggest that although the IQ-achievement discrepancy model may not be the best approach for identifying children at-risk for SLD, school psychologists should continue to use intelligence tests as part of the assessment process. The current paper (a) provides a brief review of the IQ-achievement discrepancy model, (b) reviews concerns of using intelligence tests within a RTI framework, and (c) reviews some of the major criticisms regarding the IQ-achievement discrepancy model.
\end{abstract}

Keywords - Learning Disabilities, IQ Discrepancy Model, Response-to-Intervention, school psychology, special education 
In December 2004, the United States Congress passed the Individuals with Disabilities Education Improvement Act (IDEIA, 2004), which permitted local education agencies to use a Response-to-Intervention (RTI) approach for identifying children with possible learning disabilities for special education. With the passage of IDEIA 2004, educators were essentially given the choice of using the traditional IQ-achievement discrepancy model or RTI for identifying students at-risk for a Specific Learning Disability (SLD). Unfortunately the passage of IDEIA 2004 has not resolved the debate regarding the best approach for identifying children with SLD. On one hand, some notable researchers argue that the IQ-achievement discrepancy model affords educators with the most valid approach for preserving the construct SLD and identifying those students with "real" learning disabilities (Mastropieri \& Scruggs, 2002; Kavale, 2002). On the other hand, many researchers question the validity of the IQ-achievement discrepancy model and suggest that an RTI approach is an empirically supported approach that is free of many of the criticisms associated with the IQ-achievement discrepancy model. Although RTI has been shown to be a viable approach for the identification of children at-risk for SLD, most states and local school districts continue to use the IQ-achievement discrepancy model nearly four years after the passage of IDEIA 2004 and its associated regulations. . The purpose of the current article is to (a) provide a brief review of the discrepancy model, (b) provide a compendium of the issues related to the IQ-discrepancy model for school psychology practitioners, and (c) review the issues related to the use of intelligence tests within an RTI model.

\section{Description of the Discrepancy Model}

In general, the discrepancy model employed in most states including California requires that the following four criteria are met before determining eligibility for SLD: (a) establishing a discrepancy between intellectual/cognitive ability and academic achievement, (b) identifying the existence of a psychological/cognitive processing deficit, (c) determining if the child's educational needs can or cannot be met without special education and related services, and (d) exclusionary considerations. The first part of this model is to determine if a significant discrepancy between the student's intellectual ability and academic achievement exists. Although there are a number of different methods available to determine if a significant discrepancy exists, the most common method used is to simply look at the standard scores on some measure of intellectual ability and compare them to the standard scores obtained on various measures of academic achievement. If the discrepancy between ability and achievement is equal to or greater than the pre-established criteria set forth by the state (e.g., 1 1 12 standard deviations [22 points] in California]), the student has met the first criterion for a SLD. Once the ability-achievement discrepancy criterion is met, a deficit in some area of psychological processing must be identified in order meet the second part of the SLD criteria. Areas of psychological processing include, but are not limited to, 
auditory processing, visual processing and visual-motor integration. At this point in the assessment process, school psychologists have two approaches for identifying a processing deficit. The first approach used to determine if a child demonstrates a processing deficit is to analyze their performance on the previously administered intelligence test. A review of the technical manuals of a number of intelligence tests (e.g., Wechsler Intelligence Scales for Children - $4^{\text {th }}$ edition [WISC-IV]; Wechsler, 2003, Woodcock-Johnson Tests of Cognitive Abilities - $3^{\text {rd }}$ edition [WJ-III COG]; Woodcock, McGrew, \& Mather, 2001, Cognitive Abilities Scales [CAS]; Naglieri \& Das, 1997, Kaufman Assessment Battery for Children - 2nd edition [K-ABC-II]; Kaufman \& Kaufman, 2004) report that through analysis of scales, subtests or clusters of subtests, a child's processing strengths and/or weaknesses can be identified. The second approach for detecting a psychological processing deficit is to administer a battery of tests that purport to measure different areas of psychological processing. If the student obtains a standard score that is significantly below average on any one of those measures (e.g., auditory processing), a psychological processing deficit has been identified. School psychologists for identifying processing deficits and meeting the second part of the SLD criteria frequently use both of the previously described approaches. The third part of the SLD criteria is to determine if the child has an educational need. The educational need criterion essentially requires that members of the IEP team agree that the child's educational needs will be best served if he or she is deemed eligible to receive special education services. Factors considered when making this decision are results of testing provided by the school psychologists and other professionals, efficacy of pre-referral interventions, and the opinions of members of the IEP team. At this point in the assessment and identification process, it is unlikely that any member of the IEP team would disagree with the need for special education services provided the child meets the first two criteria. The fourth criterion in the SLD identification process is exclusionary considerations. That is, the school psychologists and/or IEP team must conclude that the presence of a specific learning disability is not due to a sensory disorder, mental retardation (MR), emotional disturbance (ED), economic disadvantage, linguistic diversity, or inadequate instruction. If at any point during the assessment process, one of these variables is thought to contribute to the learning disability, eligibility for Special Education as a child with SLD should not be considered, however, special education eligibility in another category (e.g., MR or ED) may be considered.

Once the previously describes four criteria are met, the student is eligible for Special Education services as a child with an SLD. Interestingly, the Education for All Handicapped Children Act (1975; renamed the Individual with Disabilities Education Act [IDEA] in 1990) did not require the assessment of intelligence or psychological processing for determining eligibility of SLD. Although not mandated in federal law, most educators involved in this type of assessment would agree that the IQ-achievement discrepancy and identification of psychological processing strengths and weaknesses are the most 
heavily weighted considerations for identifying SLD. Although IDEA never required this type of assessment as part of SLD, the IQ-achievement discrepancy model was implemented in an arbitrary fashion in the 1977 federal regulations. This was done as a way to operationalize the construct of SLD and prevent a de facto prevalence cap of $2 \%$ from being enacted automatically (U.S. Office of Education, 1977). Admittedly, the previously described assessment process is not always so clear-cut, however, it demonstrates a common assessment process used daily by thousands of school psychologists and multi-disciplinary teams (MDT) across the United States.

Issues with the Discrepancy Model

From its inception, the discrepancy model has been problematic for numerous reasons. Over the past 30 years dozens of research articles have provided empirical evidence of the problems inherent with the IQ-achievement discrepancy model. As previously stated, the forthcoming discussion is meant to provide practitioners with a compendium of the issues related to the IQ-achievement discrepancy model and a brief review of the research literature supporting each of the points.

First and foremost, use of the discrepancy model has made early identification and intervention of children with suspected SLDs difficult. For the most part, young children experiencing academic problems in the early elementary grades do not demonstrate the IQ-achievement discrepancy necessary to meet eligibility as SLD (Speece, 2002). As a result, it is not uncommon for these students to continue to fail for an additional two or three years, and often longer, before their achievement is sufficiently low compared to their IQ and they are eligible to receive special education services. In fact, special education identification rates indicate that the odds of being classified as SLD peaks in the third and fourth grades (Lyon, Fletcher, Fuchs, \& Chhabra, 2006). This model represents a "wait-to-fail" approach, which results in the loss of valuable instructional time that would likely make a significant difference to a substantial number of the children affected (Fletcher, Lyon, Barnes, Stuebing, Francis, Olson, Shaywitz \& Shaywitz 2002; Gresham, 2002; Torgeson, Alexander, Wagner, Rashotte, Voeller, \& Conway, 2001). For example, in the area of reading, children at-risk for later reading difficulties can be reliably identified as early as the beginning of first grade (Juel, 1988). When these children are not intervened upon early in their academic careers, there is a high probability (>70\%) that they will continue to be poor readers into the secondary grades and beyond (Fletcher \& Lyon, 1998). On the other hand, when educators are able to meet the academic achievement needs of children early on, the likelihood of positive, long-term educational outcomes is greatly increased (Fletcher et al., 2002; Stanovich, 2000). Furthermore, the likelihood of negative long-term outcomes such as school dropout, delinquency, and unemployment is significantly reduced (Alexander, Entwisle, \& Horsey, 1997; Williams \& McGee, 1994). Although the ability to provide early 
intervention and prevention for all children at risk for school failure alone should justify moving to an RTI approach, it is just one of many problems with the IQ-achievement discrepancy approach for identifying SLD.

A second major criticism of the ability-achievement discrepancy model for identifying SLD is the inconsistent manner in which practitioners apply this approach. Gresham, MacMillan and colleagues concluded that over half of the school-identified SLD children included in their study did not meet federal or state eligibility criteria (Gresham, MacMillan, \& Bocian, 1996; MacMillan, Gresham \& Bocian, 1998; MacMillan \& Speece, 1999). That is, many of the children included in this study did not demonstrate a significant discrepancy, had IQ scores below 75 (i.e., mild mental retardation [MMR]), or were Emotionally Disturbed (ED). In addition, Gresham, MacMillan, and colleagues reported that an unknown number of children who did in fact meet the criteria as SLD, were not identified as such. Furthermore, a number of researchers have concluded that SLD eligibility criteria are not uniformly applied within and across states (Bocian, Beebe, MacMillan, \& Gresham, 1999; Gottlieb, Alter, Gottlieb, \& Wishner, 1994; MacMillan et al., 1998; Peterson \& Shinn, 2002). Although well intentioned, when school personnel select children for special education in such an inconsistent and subjective manner, they negate the very objectivity and precision the IQ-achievement discrepancy model proposes to offer. Furthermore, it is reasonable to assume that school personnel will continue to identify students for special education based on their perceptions regarding the individual needs of their students.

A third criticism of the IQ-achievement discrepancy approach is that many students that experience long-term academic achievement problems never receive special education services because of below average intellectual ability (i.e., slow learner). This is a problem that school psychologists working under an IQ-achievement discrepancy mandate are all too familiar with. For example, a child with an IQ score of 85 and a reading decoding score of 70 is not likely to receive special education services. In this scenario, the student's IQ score is not low enough to warrant special education placement as MR, nor do they demonstrate the necessary discrepancy between ability and achievement to qualify for special education as SLD. Although few would argue that a child with a reading standard score of 70 demonstrates an urgent need for the type of support available from special education, school psychologists and educators have been hamstrung for nearly 30 years by laws and regulations from helping a child with this all-to-common profile. The result of this scenario is that school psychologists and educators are presented with a serious, ethical dilemma. That is, to qualify a child for special education as SLD who does not meet the criteria for such a placement or to not qualify a child for services they would clearly benefit from. As a result, many school psychologists engage in questionable practices in their effort to address the academic achievement needs of such children. This conclusion is consistent with those of 
MacMillan, Gresham, Lopez, and Bocian (1996) and Gottlieb et al. (1994) who indicated that school personnel tend to base their decisions on an "absolute low achievement" criterion, thereby ignoring the discrepancy component of the law. Although use of the IQ-achievement discrepancy approach is problematic due to the previously described issues inherent in this approach, perhaps the more troubling part of the IQ-achievement equation is the use of intelligence tests for the identification of SLD at all.

A fourth criticism questions the use of intelligence tests in any manner as part of the SLD definition. Originally the rationale for including intelligence tests as part of the definition of SLD was to determine if a student's underachievement in a given area of academic achievement was expected or unexpected. This conceptualization can be traced to the Isle of Wright studies by Rutter and Yule (1975). These authors identified two types of reading underachievement difficulties that they termed general reading backwardness (GRB) and specific reading retardation (SRR). GRB was defined as reading below the level expected of a child's chronological age, whereas, SRR was defined as reading below the level predicted by a child's intelligence (i.e., discrepant underachievement). This conceptualization formed the basis for current notions of expected and unexpected underachievement.

The concept of unexpected underachievement has been a central premise in the conceptualization of SLD. That is, it is reasonable to expect that if a child performs within the average range on some measure of intelligence, that his or her ability in the various areas of academic achievement should also be in the average range. Following this logic, it is also reasonable to assume that if a child performs within the average range on some measure of intelligence, but his or her performance in an area of academic achievement is significantly below average, then his or her performance in that area would be unexpected. The latter scenario represents the most fundamental component of the construct of SLD. The logic of this, however, is based on the faulty premise that IQ and academic achievement are perfectly correlated. In fact, at best, the correlation between measures of cognitive ability and academic achievement rarely exceed .60, thereby accounting for only $36 \%$ of shared variance (Sattler, 2001). Although determining expected or unexpected underachievement was a major reason for including intelligence tests in the identification of SLD, it is now clear that establishing the discrepancy between intelligence and achievement is not particularly useful either for assessment or intervention purposes. Furthermore, over the past 30 years, the use of intelligence tests has evolved into a realm far beyond its original intent.

A fifth major criticism of the IQ-achievement discrepancy model is that there is little scientific basis for using this approach (Francis, Fletcher, \& Stuebing, 2005; Stuebing, Fletcher, LeDoux, Lyon, Shaywitz, \& Shaywitz, 2002). That is, empirical evidence demonstrating the reliability and validity of the IQ-achievement discrepancy model for 
identifying SLD is virtually non-existent (Fletcher et al., 2002; Stuebing et al., 2002; Vellutino, Scanlon, \& Lyon, 2000). On the contrary, a rather substantial body of evidence has concluded that IQ-achievement discrepancy models do not accurately identify SLD (Hoskyn \& Swanson, 2000; Stuebing et al., 2002; Vellutino et al., 2000). With respect to the reliability of the IQ-achievement discrepancy model, Fletcher et al. (2002) concluded that making a decision based on a single test score, at a single point in time, with an instrument that has measurement error is not a reliable or psychometrically sound practice. Since a student is generally administered a measure (e.g., IQ or achievement test) only once, the repeated measures necessary to establish the reliability (consistency) of their performance cannot be determined. Without repeated measures, issues such as examinee characteristics, examiner characteristics, and situational conditions are difficult to account for, making the reliability of the IQ-achievement discrepancy models particularly problematic. In discussing the unreliability of the discrepancy approach, Shepard (1980) proposed that students be administered at-least four separate combinations of $I Q$ and achievement tests in order to derive a reliable estimate of the student's discrepancy score. However, this procedure would take school psychologists up to 12 hours of testing just on IQ and achievement tests, which does not have much practical appeal.

With regard to validity, a substantial body of research has concluded that using an IQachievement discrepancy approach does not accurately identify discrepant low achievers from non-discrepant low achievers (Fletcher et al., 2002; Francis, Shaywitz, Stuebing, Shaywitz, \& Fletcher, 1996; Hoskyn \& Swanson, 2000; Vellutino et al., 2000). This indicates that the discrepancy model is not valid for the purposes of identifying SLD. Most researchers would agree that discrepant and non-discrepant low-achievers differ to some degree. The central issue is to determine whether or not those differences are meaningful enough to warrant continued research and to influence practice. A consistent theme when reviewing the research literature pertaining to discrepant versus non-discrepant low-achievers is how to distinguish the "real LD" students from the lowachieving students. It appears that we have become so intent on preserving the construct of LD, as arbitrarily operationalized by the discrepancy model that we seem to have forgotten that the more important goal is to help children who are struggling academically. Whereas studies comparing IQ discrepant and non-discrepant students have demonstrated no meaningful differences between the two groups, studies of students defined as responders and non-responders to interventions using RTI procedures have clearly demonstrated differences on key variables among the groups. For example, Stage, Abbott, Jenkins, and Berninger (2003), Vellutino et al. (2000), and Vaughn, Linan, Thompson, and Hickman (2003) all found that non-responders to early intervention differed from responders in both pre-intervention achievement scores and pre-intervention cognitive tasks. Moreover, Fletcher, Coulter, Reschly, and Vaughn (2004) found through neuroimaging procedures that intervention non-responders tend to have 
deficient left hemispheric activity in areas of the brain that are consistent with the development of reading skills, providing further evidence of the differentiation between responders and non-responders to high quality interventions. Previous research also suggests that the discrepancy approach lacks strong evidence for external validity with respect to achievement, behavior, neuro-biological factors, prognosis, and response to intervention (Fletcher et al., 2002).

\section{IQ Tests and RTI}

A number of researchers have argued that IQ tests should continue to be an integral component of a comprehensive assessment for identifying children with suspected learning disabilities (Flanagan, Ortiz, Alfonso, \& Dynda, 2006; Hale, Naglieri, Kaufman, \& Kavale, 2006). More specifically, these researchers posit that children who do not respond to research-based interventions within an RTI framework should be given intelligence tests to help school psychologists and other invested professionals identify the cognitive or psychological processes that are adversely impacting the child's academic performance. With this perspective in mind, we believe that there a number of reasons why IQ tests should not necessarily be included as part of the assessment process for children who have not responded to interventions in the initial phases of the RTI process.

First, as previously stated, the authors and publishers of popular intelligence tests such as the WISC-IV, CAS, and W-J III COG assert that their measures can assist school psychologists and other educators in identifying the cognitive or psychological processes that have lead to a child's academic underachievement (Kaufman \& Kaufman, 2004; Naglieri \& Das, 1997, 2005; Woodcock, McGrew, \& Mather, 2001). Furthermore, these researchers posit that once these underlying processing strengths and weaknesses are identified, those instructional treatments can be developed to produce positive academic achievement outcomes. The assumption that instructional treatments can be matched to aptitudes or cognitive processes to produce unique and positive academic outcomes is not new. This idea can be traced back to Cronbach's research on aptitude $x$ treatment interactions (ATI; Cronbach 1957, 1975). The basic logic of ATIs is that instructional treatments can be matched to aptitudes or modalities (e.g., auditory processing, visual processing). It is believed that if instructional treatments are matched to processing strengths or that if aptitude weaknesses are targeted for remediation, improved academic performance will result. Although the idea of matching instructional treatments to aptitudes is intuitively appealing, empirical evidence supporting the existence of ATIs is spurious and for the most part, nonexistent (Ayers \& Cooley, 1986; Cronbach, 1975; Gresham, 2002; Kavale \& Forness, 1987). Despite the fact that there is a paucity of research supporting the existence of ATIs, school psychologists continue to focus on cognitive strengths and weaknesses and their 
presumed relevance to treatment. We have reached a point in school psychology and education that when we discuss a child's achievement difficulties, we automatically attribute the child's difficulties to some "processing deficit" inherent within the child. Intelligence tests were originally developed to determine individuals' overall cognitive ability and used by educators to determine special education eligibility (i.e., expected versus unexpected underachievement). However, school psychologists now regularly use and "interpret" intelligence tests for the purposes of identifying the processing strengths and weaknesses that "cause" a child to perform poorly in some area of academic achievement.

Developers of popular intelligence tests such as the CAS (Naglieri \& Das, 1997), WISC-IV (Wechsler, 2003), KABC-II (Kaufman \& Kaufman, 2004), and the W-J III COG (McGrew et al., 2001) actually discourage the use of their overall scores (i.e., Full Scale IQ). Instead, they strongly urge the user to use their tests for the purposes of identifying processing strengths and weaknesses. These authors imply that their tests are not necessarily measures of intelligence, but rather measures of processing. Ironically, when these tests were validated, they are not validated against other tests purporting to measure similar constructs such as auditory processing or memory, but rather, against other well established tests of intelligence. Advocates of intelligence testing argue that the core procedure of a comprehensive evaluation of LD is an objective, norm-referenced assessment of the presence and severity of any cognitive processing strengths and weaknesses (Flanagan et al., 2006; Hale et al., 2006). However, there is no corpus of evidence to support such a practice to enhance SLD identification, control prevalence, translate into more effective instruction, or improve prediction of the outcomes of interventions. Absent such evidence, the benefits of intelligence and psychological process testing simply do not outweigh the costs in terms of school personnel time, resources, and student outcomes (Gresham \& Witt, 1997; Reschly \& Wilson, 1995).

A second important issue regarding the use of intelligence tests within an RTI framework pertains to the manner in which the authors of intelligence tests recommend that we use their measures. As previously stated, the authors and publishers of intelligence tests have assured users that by using their methods of interpretation, their tests can help identify processing strengths and weaknesses. Additionally, in doing so test users can create instructional interventions that will help children that are struggling academically to improve their academic performance. Methods of interpretation recommended by Kaufman and others include ipsative or profile analysis (i.e., subtest analysis) (Kaufman, 1994). The two common methods of subtest analysis involve: (a) comparing individual subtest scores to the unique mean subtest score of the child and (b) directly comparing one subtest score to another for the purposes of identifying specific patterns of subtest scores. Proponents of subtest analysis posit that subtest scores that are significantly higher or lower than a child's own average are considered relative and/or cognitive 
strengths and weaknesses. Additionally, certain subtest patterns are thought to be unique and indicative of learning and emotional problems. Although a thorough review of the subtest analysis literature is beyond the scope of this paper, research on the topic has reached the following conclusions. First, subtests have low reliability and specificity, therefore, making decisions regarding cognitive strengths and weaknesses based on the scores produced from these measures is an unsound practice (Macmann \& Barnett, 1997; Watkins, Glutting \& Youngstrom, 2005). Second, ipsative subtest scores do not contribute anything to the prediction of academic achievement not already accounted for by the global Full Scale score (Macmann \& Barnett, 1997; McDermott, Fantuzzo \& Glutting, 1990). Third, ipsative scores cannot be interpreted as if they possess the same psychometric properties as normative scores; therefore, such interpretation is not recommended (McDermott \& Glutting, 1997; Watkins et al., 2005). Fourth, it is not uncommon for children to demonstrate a considerable degree of variation across subtests; thus, using score differences obtained from subtests should not be used to make diagnostic decisions. Fifth, not all children from a particular diagnostic category will exhibit the profile thought to be unique to that diagnostic category (Watkins et al., 2005). Overall, proponents of subtest analysis have not adequately demonstrated that this practice has adequate reliability, diagnostic utility, or treatment validity. Despite overwhelming evidence to the contrary, many school psychologists continue to use, or rather, misuse intelligence tests in a manner that is inconsistent with these research findings.

A third issue regarding the use intelligence testing within an RTI framework is the assumption that RTI alone will not provide the information necessary to develop appropriate interventions for students who do not respond sufficiently to initial attempts to prevent or remediate their academic and/or behavioral difficulties. Proponents of intelligence testing argue that without IQ tests and other measures of psychological processing, school psychologists and teachers will not have the necessary information needed for developing interventions for children experiencing academic difficulties (Flanagan et al., 2006; Hale et al., 2006). Specifically, these researchers argue that children who do not respond to research-based interventions within an RTI framework should be given intelligence tests to help identify the cognitive/psychological processes that are causing their academic underachievement. Although recently a number of these researchers have conceded that the discrepancy approach for identifying SLD is flawed beyond repair, they now insist that measures of intelligence and psychological processing complement RTI. Proponents of RTI would argue that whether used within a discrepancy approach or not, measures of intelligence or psychological processing do not add information necessary for developing instructional interventions (Fletcher et al., 2004; Gresham, 2006; National Association of State Directors of Special Education, 2005; Reschly \& Ysseldyke, 2002). In short, most proponents of RTI take issue not only with the use of IQ tests within an IQ-achievement discrepancy approach, but with the use of IQ 
tests in and of themselves for the purposes of assessing SLD. It is precisely because of the failure of measures of intelligence and psychological processing to provide school psychologists and teachers with the information necessary to develop instructional interventions that researchers were compelled to seek and explore alternative approaches for identifying SLD. One such approach was RTI. Within an RTI approach, instead of asking, "what kind of processing deficit does the child have?," we ask, "what kind of problems is the child demonstrating, where and when do they occur, and what can we do about it?"

\section{Conclusion}

Many researchers and practitioners in school psychology and special education would agree that moving from a classification and/or eligibility-based assessment approach to one that focuses on intervention would be in the best interest of children experiencing academic achievement difficulties (e.g., Burns \& Ysseldyke, 2005; Fuchs, Mock, Morgan, \& Young, 2003; Gresham, 2001, 2002, 2005; Kovaleski \& Prasse, 2004). In light of the numerous problems with the IQ-achievement discrepancy model, RTI may offer the most viable approach for making this shift. RTI has not only garnered the support of many researchers and practitioners across the country, but it has been endorsed by the President's Commission on Excellence in Special Education (PCESE, 2001) and the National Association of School Psychologists (NASP, 2007).

RTI offers an improved approach to assessment that allows educators to help children they know are struggling and does not include circumventing the problems that many school psychologists and special education teachers must face when using the IQachievement discrepancy approach. Further, an RTI approach to eligibility determination moves away from using measures that yield minimal benefits with respect to treatment. The RTI approach instead focuses on direct measures of student achievement and the instructional environment that produce data that are in the best interest of both the children served and the educators that serve them. The data resulting from the application of RTI methods allow school psychologists and teachers to focus on issues related to intervention, rather than issues related to classification and eligibility. Although RTI is not a perfect system, it is an approach with promising empirical support, which is not the case for the traditional testing-oriented discrepancy model. The authors of this paper have been unable to locate an empirically based rationale for the inclusion of measures of intelligence or psychological processing within a properly conducted RTI approach. The time has come for making the paradigm shift that Reschly and Ysseldyke (2002) spoke of over seven years ago. 


\section{References}

Alexander, K. L., Entwisle, D. R., \& Horsey, C. S. (1997). From first grade forward: Early foundations of high school dropout. Sociology of Education, 70, 87-107.

Ayers, R. R., \& Cooley, E. J. (1986). Sequential versus simultaneous processing on the K$A B C$ : Validity in prediction learning success. Journal of Psychoeducational Assessment, 4, 211-220.

Bocian, K. M., Beebe, M. E., MacMillan, D. L., \& Gresham, F. M. (1999). Competing paradigms in learning disabilities classification by schools and the variations in the meaning of discrepant achievement. Learning Disabilities Research and Practice, 14, 114.

Burns, M. K., \& Ysseldyke, J. E. (2005). Comparison of existing responsiveness-tointervention models to identify and answer implementation questions. The California School Psychologist, 10, 9-20.

Cronbach, L.J. (1957). The two disciplines of scientific psychology. American Psychologist, 12, 671-684.

Cronbach, L.J. (1975). Beyond the two disciplines of scientific psychology. American Psychologist, 30, $116-127$.

Education for All Handicapped Children Act, Pub. L. No. 94-142 (1975). Regulations appeared in 1977.

Flanagan, D. P., Ortiz, S. O., Alfonso, V. C., \& Dynda, A. M. (2006). Integration of response to intervention and norm-referenced tests in learning disability identification: Learning from the Tower of Babel. Psychology in the Schools, 43, 807-825.

Fletcher, J. M., Coulter, W. A., Reschly, D. J., \& Vaughn, S. (2004). Alternative approaches to the definition and identification of learning disabilities: Some questions and answers. Annals of Dyslexia, 54, 304-331.

Fletcher, J. M., \& Lyon, G. R. (1998). Reading: A research-based approach. In W. M. Evers (Ed.), What's gone wrong in America's classrooms (pp.49-90). Stanford, CA: Hoover Institution Press.

Fletcher, J. M., Lyon, G. R., Barnes, M., Stuebing, K. K., Francis, D. J., Olson, R. K., Shaywitz, S. E., \& Shaywitz, B. A. (2002). Classification of learning disabilities: An evidence-based 
evaluation. In R. Bradley, L. Danielson, \& D. Hallahan (Eds.), Identification of learning disabilities: Research to practice (pp. 467-519). Mahwah NJ: Erlbaum.

Francis, D. J., Fletcher, J. M., \& Stuebing, K. K. (2005). Psychometric approaches to the identification of LD: IQ and achievement scores are not sufficient. Journal of Learning Disabilities, 38, 98-108.

Francis, D. J., Shaywitz, S. E., Stuebing, K. K., Shaywitz, B. A., \& Fletcher, J. M. (1996). Developmental lag versus deficit models of reading disability: A longitudinal individual growth curves analysis. Journal of Learning Disabilities, 24, 495-500.

Fuchs, D., Mock, D., Morgan, P. L., \& Young, C. L. (2003). Responsiveness-to-intervention: Definitions, evidence, and implications for the learning disabilities construct. Learning Disabilities Research \& Practice, 13, 204-219.

Gottlieb, J., Alter, M. Gottlieb, B., \& Wishner, J. (1994). Special education in urban America: It's not justifiable for many. Journal of Special Education, 27, 453-465.

Gresham, F. (2001). Responsiveness to intervention: An alternative to the identification of learning disabilities. Paper presented at the 2001 Learning Disabilities Summit: Building a Foundation for the Future. Retrieved March 8, 2007, from

http://www.air.org/ldsummit/download.

Gresham, F. M. (2002). Responsiveness to intervention: An alternative approach to the identification of learning disabilities. In R. Bradley, L. Donaldson, \& D. Hallahan (Eds.), Identification of learning disabilities: Research to practice (pp. 467-519). Mahwah, NJ: Erlbaum.

Gresham, F. M. (2005). Response to intervention: An alternative means of identifying students as emotionally disturbed. Education and Treatment of Children, 28, 328-344.

Gresham, F. M. (2006). Response to intervention. In G. Bear \& K. Minke (Eds.), Children's needs III (pp. 525-540). Bethesda, MD: National Association of School Psychologists.

Gresham, F. M., MacMillan, D. L. \& Bocian, K. M. (1996). Learning disabilities, low achievement, and mild mental retardation: More alike than different? Journal of Learning Disabilities, $29(6), 570-581$.

Gresham, F. M., \& Witt, J. C. (1997). Utility of intelligence tests for treatment planning, classification, and placement decisions: Recent empirical findings and future directions. School Psychology Quarterly, 12, 249-267. 
Hale, J. B., Kaufman, A., Nagileri, J. A., \& Kavale, K. A. (2006). Implementation of IDEA: Integrating response to intervention and cognitive assessment methods. Psychology in the Schools, 43, 753-770.

Hoskyn, M., \& Swanson, H. L. (2000). Cognitive processing of low achievers and children with reading disabilities. A selective meta-analytic review of the published literature. School Psychology Review, 29, 102-119.

Individuals with Disabilities Education Act, Pub. L. 101-476 (1990).

Individuals with Disabilities Education Improvement Act, Pub. L. 108-446 (2004).

Juel, C. (1988). Learning to read and write: A longitudinal study of 54 children from first to fourth grades. Journal of Educational Psychology, 80, 437-447.

Kaufman, A.S. (1994). Intelligent testing with the WISC-III. New York: Wiley.

Kaufman, A. S., \& Kaufman, N. L. (2004). Manual for the Kaufman Assessment Battery for Children - Second Edition (KABC-II), Comprehensive Form. Circle Pines, MN: American Guidance Service.

Kavale, K. (2002). Discrepancy models in the identification of learning disability. In R. Bradley, L. Donaldson, \& D. Hallahan (Eds.), Identification of learning disabilities: Research to practice (pp. 369-426). Mahwah, NJ: Erlbaum.

Kavale, K. A., \& Forness, S. R. (1987). Substance over style: A quantitative synthesis assessing the efficacy of modality testing and teaching. Exceptional Children, 54, 228234.

Kovaleski, J., \& Prasse, D. P. (2004). Response to instruction in the identification of learning disabilities: A guide for school teams. Communiqué, 32(5), 14-18.

Lyon, G. R., Fletcher, J. M., Fuchs, L. S., \& Chhabra, V. (2006). Learning disabilities. In E.J. Mash \& R. Barkley (Eds.). Treatment of childhood disorders (3rd ed., pp. 512-594). Hillsdale, NJ: Erlbaum.

Mash \& R. Barkley (Eds.), Treatment of childhood disorders (pp. 512-591). NY: Guildford Press.

Macmann, G. M., \& Barnett, D. W. (1997). Myth of the master detective: Reliability of interpretations of Kaufman's "intelligence testing" approach to the WISC-III. School Psychology Quarterly, 12, 197-234. 
MacMillan, D. L., Gresham, F. M., \& Bocian, K. M. (1998). Discrepancy between definitions of learning disabilities and school practices: An empirical investigation. Journal of Learning Disabilities, 31, 314-326.

MacMillan, D. L., Gresham, F. M., Lopez, M. F., \& Bocian, K. M. (1996). Comparison of students nominated for prereferral interventions by ethnicity and gender. The Journal of Special Education, 30, 133-151.

MacMillan, D. L., \& Speece, D. (1999). Utility of current diagnostic categories for research and practice. In R. Gallimore, C. Bernheimer, D. MacMillan, D. Speece, \& S. Vaughn (Eds.), Developmental perspectives on children with high incidence disabilities (pp. 111 133). Mahwah NJ: Lawrence Erlbaum.

Mastropieri, M. A., \& Scruggs, T. E. (2002). Discrepancy models in the identification of learning disability: A response to Kavale. In R. Bradley, L. Donaldson, \& D. Hallahan (Eds.), Identification of learning disabilities: Research to practice (pp. 449-455). Mahwah, NJ: Erlbaum.

McDermott, P. A., Fantuzzo, J. W., \& Glutting, J. J. (1990). Just say no to subtest analysis: A critique on Wechsler theory and practice. Journal of Psychoeducational Assessment, 8 , 290-302.

McDermott, P. A., \& Glutting, J. J. (1997). Informing stylistic learning behavior, disposition, and achievement through ability subtests - or, more illusions of meaning? School Psychology Review, 26, 163-175.

Naglieri, J. A., \& Das, J. P. (1997). Cognitive Assessment System. Chicago: Riverside Publishing.

Naglieri, J. A., \& Das J. P. (2005). Planning, Attention, Simultaneous, Successive (PASS) theory: A revision of the concept of intelligence. In D. Flanagan \& P. Harrison (Eds.), Contemporary intellectual assessment: Theories, tests, and issues (pp. 120-136). New York: Guilford Press.

National Association of State Directors of Special Education (2005). Response to intervention: Policy considerations and implementation. Alexandria, VA: National Association of State Directors of Special Education, Inc.

National Association of School Psychologists (2007). NASP position statement on identification of students with specific learning disabilities. Bethesda, MD: National Association of School Psychologists. 
Peterson, K. M. H., \& Shinn, M. R. (2002). Severe discrepancy models: Which best explains school identification practices for learning disabilities? School Psychology Review, 31 , 459-476.

President's Commission on Excellence in Special Education. (2001). A new era: Revitalizing special education for children and their families. Washington D.C.: Department of Education.

Reschly, D. J., \& Wilson, M. S. (1995). School psychology practitioners and faculty: 1986 to 1991-92 trends in demographics, roles, satisfaction, and system reform. School Psychology Review, 24, 62-80.

Reschly, D. J., \& Ysseldyke, J. E. (2002). Paradigm shift: The past is not the future. In A. Thomas, \& J. Grimes (Eds.), Best practices in school psychology IV (pp. 3-20). Bethesda, MD: National Association of School Psychologists.

Rutter, M., \& Yule, W. (1975). The concept of specific reading retardation. Journal of Child Psychology and Psychiatry, 16, 181-197.

Sattler, J. M. (2001). Assessment of children: Cognitive applications. San Diego, CA: Jerome Sattler Publisher.

Shepard, L. (1980). An evaluation of the regression discrepancy method for identifying children with learning disabilities. Journal of Special Education, 14, 79-91.

Speece, D. (2002). Classification of learning disabilities: Convergence, expansion, and caution. In R. Bradley, L. Danielson, \& D. Hallahan (Eds.), Identification of learning disabilities: Research to practice (pp. 467-519). Mahwah NJ: Erlbaum.

Stage, S. A., Abbott, R. D., Jenkins, J. R., \& Berninger, V. W. (2003). Predicting response to early reading intervention from verbal $I Q$, reading-related language abilities, attention ratings, and verbal IQ-word reading discrepancy: Failure to validate discrepancy method. Journal of Learning Disabilities, 36, 24-33.

Stanovich, K. E. (2000). Progress in understanding reading: Scientific foundations and new frontiers. New York: Guilford Press.

Stuebing, K. K., Fletcher, J. M., LeDoux, J. M., Lyon, G. R., Shaywitz, S. E., \& Shaywitz, B. A. (2002). Validity of IQ-discrepancy classification of reading disabilities: A meta-analysis. American Educational Research Journal, 39, 469-518. 
Torgeson, J. K., Alexander, A. W., Wagner, R. K., Rashotte, C .A., Voeller, K. K., \& Conway, T. (2001). Intensive remedial instruction for children with severe reading disabilities: Immediate and long-term outcomes from two instructional approaches. Journal of Learning Disabilities, 34, 33-58, 78.

U.S. Office of Education. (1977). Assistance to states for education of handicapped children: Procedures for evaluating specific learning disabilities. Federal Register, 42 (250), 65082-65085.

Vaughn, S., Linan-Thompson, S., \& Hickman, P. (2003). Response to instruction as a means of identifying students with reading/learning disabilities. Exceptional Children, 69, 391409.

Vellutino, F. R., Scanlon, D. M., \& Lyon, G. R. (2000). Differentiating between difficult-toremediate and readily remediated poor readers: More evidence against the IQachievement discrepancy definition for reading disability. Journal of Learning Disabilities, 33, 223-238.

Watkins, M. W., Glutting, J. J., \& Youngstrom, E. A. (2005). Issue in subtest profile analysis. In D. Flanagan \& P. Harrison (Eds.), Contemporary intellectual assessment: Theories, tests, and issues (pp. 251-268). New York: The Guilford Press.

Wechsler, D. (2003). Wechsler Intelligence Scale for Children - Fourth Edition: Technical and interpretive manual. San Antonio, TX: Psychological Corporation.

Williams, S., \& McGee, R. (1994). Reading attainment and juvenile delinquency. Journal of Child Psychology and Psychiatry, 35, 441-459.

Woodcock, R. W., McGrew, K. S., \& Mather, N. (2001). Examiner's manual. WoodcockJohnson III Tests of Cognitive Ability. Itasca, IL: Riverside Publishing.

About the authors:

Alberto F. Restori, Ph.D. is an Associate Professor of School Psychology in the Department of Educational Psychology at California State University, Northridge. Dr. Restori received his Ph.D. at the University of California at Riverside.

Email address is alberto.restori@csun.edu.

Postal address: Department of Educational Psychology and Counseling, CSUN, 18111 Nordhoff Street, Northridge, CA 91330-8265. 
Gary S. Katz is an Assistant Professor of Psychology in the Department of Psychology at California State University, Northridge. Dr. Katz received his doctorate in clinical psychology from the University of Pittsburgh. His email address is gary.katz@csun.edu

Howard B. Lee, Ph.D. is a professor of psychology in the department of psychology at California State University, Northridge. Dr. Lee received his doctorate from UCLA in Psychometrics and Measurement. His email address is howard.lee@csun.edu 